\title{
Remarks on Ludwig Wittgenstein and Behaviourism
}

Susan Byrne

ABSTRACT

Ludwig Wittgenstein's systematic rejection of cognitive analysis undoubtedly leads one to interpret his work as being fundamentally influenced by behaviourism. However, despite his private language argument, his views on ostensive definition, and his investigation into psychological concepts and psychology as an empirical science, this paper will show that Wittgenstein's behaviourist influences were both relevant and limited and thus his tentative link to methodological behaviourism should not facilitate any distortion or misrepresentation of his philosophy or be confused with his own assertions as a logical behaviourist.

Ludwig Wittgenstein is considered by many to be the most influential philosopher of the twentieth century. A mathematician and an original and revolutionary philosopher of extraordinary genius, he proposed two philosophies that were equally influential yet diametrically opposed, one expressed in Tractatus Logico Philosophicus (1926), and the other in Pbilosopbical Investigations (1953). Although distinct in origin and argument there is clear evidence of Wittgenstein's continuity in thought with regard to language and to his ongoing investigation in to ontology, semantics and syntax. Although a calculus view of language is presented in the Tractatus and not in the Investigations, his analogy of a game of chess is used both in his earlier and later works to describe the workings of language, and thus, as Glock argues, it should be considered that the Investigations transforms rather than abandons the Tractatus's methodological ideas ${ }^{1}$. Testimony to this is Wittgenstein's return to philosophy and his abandonment of not only logical atomism - the idea that the possibility of representation rests on the existence of sempiternal objects - but also the idea that representation presupposes an agreement in form between a proposition and a possible state of affairs. He continued to discuss the relationship between propositions and facts, but now as a special case of intentionality, the "harmony between thought and reality' which obtains equally between beliefs, expectations, desires, etc., and what verifies or fulfils them²:

'The agreement, the harmony, of thought and reality consists in this:

if I say falsely that something is red, even the red is what it isn't.

And when I want to explain the word 'red' to someone, in the sentence

'That is not red', I do it by pointing to something red'3.

However although Wittgenstein's conception of two language systems are separate and distinct, the systems are nonetheless unified in sharing several features of commonality.

The term 'family resemblance' is an influential and significant concept across the domains of both philosophy and psychology but for Wittgenstein it characterises the conception of language (rather than only language), proposition and rules. He argues that there is no one defining feature to the meaning of a word:

'I can think of no better expression to characterise these similarities than 'family resemblance; for the various resemblances between

${ }^{1}$ Glock, H. A Wittgenstein Dictionary, Oxford: Blackwell Publishing, 1996: 27.

2 Glock, H. A Wittgenstein Dictionary, Oxford: Blackwell Publishing, 1996: 185.

${ }^{3}$ Wittgenstein, Ludwig Philosophical Investigations, Oxford: Blackwell, 1953: \#429.

(C) - Susan Byrne 'Remarks on Ludwig Wittgenstein and Behaviourism', in Maynooth Philosophical Papers, Issue 5 (2008), ed. by Simon Nolan (Maynooth: Department of Philosophy, National University of Ireland, Maynooth, 2009), pp. 49-56. 
members of a family: build, features, colour of eyes; gait, temperament, etc. overlap and criss-cross in the same way' ${ }^{4}$.

Wittgenstein applies the term family resemblance to all language-games, and in so doing avoids the possibility of any dissimulation arising in language use. However, he does not deny that identical words have different meanings (homographs) and separates this issue from the notion of ambiguity. His concept of family resemblance, and his arguments that there are no defining features or fundamental essence in order that we may define concepts, are an attack on essentialism, i.e. all concepts appropriately used refer to a common underlying essence that make the thing what it is. But how does Wittgenstein form the concept family resemblance? Arguably, the formation of this concept is fuelled by his anti-dogmatic approach to both language and philosophy (in contrast to his logical, analytical and quasi-realist approach in Tractatus Logico Pbilosophicus) which is further compounded by his attack on essentialism. Furthermore, it can be argued that Wittgenstein's anti-essentialist approach is also a rejection of Plato's Forms.

A further extension of Wittgenstein's notion of family resemblance is clearly exemplified in his key concept language-game. The term language-game appeared first in a Cambridge lecture (1932) which was then later, amongst other lectures, dictated to two of Wittgenstein's pupils (Francis Skinner and Alice Ambrose) ${ }^{5}$. In The Brown Book language-games are first explained as 'ways of using signs' and a system of communication. For Wittgenstein a language-game is not a doctrine or a theory of language, and to consider it as a theoretical notion or as a key constituent part of a theory to explain language is a further misconception of his work. But one must question whether it is possible to give an accurate description of a language-game at all? Here one is reminded of when Wittgenstein asks:

'What does it mean to know what a game is? What does it mean, to know it and not be able to say it? Is this knowledge somehow equivalent to an unformulated definition? So that if it were formulated I should be able to recognise it as the expression of my knowledge? Isn't my knowledge, my concept of a game, completely expressed in the explanations that I could give? That is, in my describing examples of various kinds of game; shewing how all sorts of other games can be constructed on the analogy of these; saying that I should scarcely include this or this among games; and so on ${ }^{6}$

For Wittgenstein, the technique of language-games was to break the tendency, and thus the expectation, of being able to answer questions such as: 'What is time?', 'What is meaning?', 'What is thought?' and 'What are numbers?' Connected with the inclination to look for a substance corresponding to a substantive is the idea that, for any given concept, there is an 'essence' - something that is common to all the things subsumed under a general term. In the Blue Book one can see clearly how Wittgenstein seeks to replace this notion of essence with the more flexible idea of family resemblances. The search for essences is an example of the 'craving for generality' that springs from our preoccupation with the method of science ${ }^{7}$. Furthermore, language

\footnotetext{
4Ibid.: \#67

${ }^{5}$ R.R., cited in: Wittgenstein, L. The Blue and Brown Books - Preliminary Studies for the Philosophical Investigations', Oxford: Blackwell, 1958: v.

${ }^{6}$ Wittgenstein, Ludwig Philosophical Investigations, Oxford: Blackwell, 1953: \#75.

${ }^{7}$ Monk, R. Ludwig Wittgenstein - The Duty of Genius, London: Vintage, 1991: 336
} 
functions in life, and so his term 'form of life' or a 'life-form' evolves': words acquire meaning as part of an activity or as part of a form. What is interesting to acknowledge here is that his term 'form of life' appears a mere five times in the Investigations' and yet here again one can see how Wittgenstein has been misrepresented as a behaviourist rather than a philosopher describing a form of behaviour - such as 'language' or 'ostension', and similarly often the language-game itself is seen as a 'game' and thus a tool for examining and understanding 'behaviour'.

Wittgenstein's interest in psychology as a philosopher has fuelled many debates about his behavioural viewpoints. His interest in this discipline is exemplified clearly in many of his works, such as: The Blue and Brown Books, Remarks on the Philosophy of Psychology Volumes $1 \& 2$, and Part II of the Investigations. However, despite his significant and relentless attention in this area, Wittgenstein rejects all cognitive analysis and asserts that philosophy is not a cognitive discipline (thus his failure to address the biological aspect of language development ${ }^{10}$ ). Glock maintains that there are no propositions expressing philosophical knowledge - and cannot emulate the methods of science.....Wittgenstein's methodological views are based on the conviction that, unlike science, philosophy is concerned not with truth, or matters of fact, but with meaning ${ }^{11}$. Wittgenstein's main concern in the Investigations can be found in language and behaviour, a language system that is essentially a theory of language, that is, a language-game view of life. Ray Monk describes the language-game as 'a (usually fictitious) primitive form of language in which one particular aspect of our language - say, the role of names - is highlighted by being separated from the complicated contexts in which it is usually embedded. The idea is that we will be able to 'see the connection' between this simplified case and language as it is used in real life' ${ }^{12}$. For Wittgenstein philosophical problems evince conceptual confusions which arise out of the distortion or misapprehension of words with which we are perfectly familiar outside philosophy. These problems should not be answered by constructing theories, but dissolved by describing the rules for the use of the words concerned $^{13}$.

Wittgenstein clearly understands the role of context in an account of linguistic interaction; nonetheless, he uses the term 'context' sparingly. Yet again, in the Investigations this term 'context' appears only six times and always in the ordinary rather than the technical sense. This is so because he idiosyncratically reconceptualises linguistic interaction in terms of language-games and forms of life. Thus, according to Wittgenstein, a hierarchy of embedding consists of words and expressions embedded in language-games, which in turn, are embedded in a variety of forms of life (for instance, biological, social or cultural) ${ }^{14}$. In the Investigations he is concerned with how the role of language is involved in human behaviour, thus the Investigations becomes his investigation into the workings of language and grammar, rather than an investigation into behaviour despite the argument that in order to ascertain whether one understands a concept or word one is directed towards another's behaviour for the answer. Fundamentally, knowledge of language and language use are seen not only in linguistic terms but also in the behaviour of the individual: to fully grasp and understand a word is to be able to use

\footnotetext{
${ }^{8}$ Wittgenstein, Ludwig Philosophical Investigations, Oxford: Blackwell, 1953: \#19

${ }_{9}^{9}$ Curry, Michael R.: in Orang, M., Thrift, N., (eds) Thinking Space, London: Routledge, 2000: 89.

10 Hathcock, D. Wittgenstein, Behaviourism, and Language Acquisition; http://www.drury.edu/multinl/story.cfm?ID=2435\&NLID=166, 2000.

${ }_{11}$ Glock, H. A Wittgenstein Dictionary, Oxford: Blackwell Publishing, 1996: 27.

${ }^{12}$ Monk, R., How to Read Wittgenstein, London: Granta Books, 2005: 74.

13 Glock, H. A Wittgenstein Dictionary, Oxford: Blackwell Publishing, 1996: 27.

${ }^{14}$ Kopytko, R. Philosophy and Pragmatics: A Language-game with Ludwig Wittgenstein, Journal of Pragmatics, 39 (2007) 792-812.
} 
it; the ability to use is actualised and shown in the using and thus this use is reflected in behaviour.

Analytical or logical behaviourism, with its historical roots in logical positivism as exemplified in the earlier work of Wittgenstein, is a theory within philosophy about the meaning or semantics of mental terms or concepts. It states that the very idea of a mental state or condition is the idea of a behavioural disposition or family of behavioural tendencies (could this term be aligned to Wittgenstein's concept 'family resemblance'?). For example, when a belief is attributed to someone, one is not saying that he or she is in a particular internal state or condition. Instead one is characterising the person in terms of what he or she might do in particular situations or environmental interactions. This type of behaviourism - analytical - can be seen clearly in the work of Gilbert Ryle (1900 - 1976) and arguably a version of this type of behaviourism can also be traced in the work of Daniel Dennett on the ascription of states of consciousness via a method he calls 'heterophenomenology'. Similarly, Willard Van Orman Quine took a behaviourist approach to the study of language. He claimed that the notion of psychological or mental activity has no place in a scientific account in either the origins or the meaning of speech. To talk in a scientifically disciplined manner about the meaning of an utterance is to talk about stimuli for the utterance, its so-called 'stimulus meaning' ${ }^{15}$. However, this interpretation of analytic or logical behaviourism raises the question of whether Wittgenstein actually fitted this category? Would it be more accurate to suggest that Wittgenstein has been misinterpreted as a behaviourist in the psychological sense rather than any philosophical one? Furthermore, according to behaviourism, mental state descriptions are really disguised or shorthand versions of behavioural descriptions. Thus, they cannot be invoked to explain the same chunks of behaviour. Aside from providing a rich description of mental phenomena throughout the Investigations, Wittgenstein himself explicitly rejects the accusation ${ }^{16}$ :

'Are you not really a behaviourist in disguise? Aren't you at bottom really saying that everything except human behaviour is a fiction? - If I do speak of a fiction, then it is of a grammatical fiction'17

Furthermore, Wittgenstein asks how does the philosophical problem - even if it is only conceptual - about mental processes and states, and about behaviourism arise?

The first step is he one that altogether escapes notice. We talk of processes and states and leave their nature undecided. Sometimes perhaps we shall know more about them - we think. But that is just what commits us to a particular way of looking at the matter. For we have a definite concept of what it means to learn to know a process better.....So we have to deny the yet uncomprehended process in the yet unexplored medium. And now it looks as if we had denied mental processes. And naturally we don't want to deny them ${ }^{18}$.

Here Wittgenstein acknowledges - to an extent - that there is more to know

\footnotetext{
${ }^{15}$ Stanford Encyclopedia of Philosophy: Behaviourism: http://plato.stanford.edu/entries/behaviourism/, 2007.

16 Thornton, T. Wittgenstein on Language and Thought: The Philosophy of Content, ,Edinburgh: Edinburgh University Press: 1988: 120.

17 Wittgenstein, Ludwig Philosophical Investigations, Oxford: Blackwell, 1953: \#307.

18 Ibid. \# 308.
} 
about the nature, and perhaps arguably 'essence', of mental processes and states even if for now one must deny the 'uncomprehended process' in the 'unexplored medium'. One could reasonably suggest here that in light of the developments within cognitive psychology as a science that the then 'uncomprehended process' is now considered to be mental processes such as attention, perception, memory, knowledge, reasoning and language, and that the 'unexplored medium' refers to the mind?

Wittgenstein's later philosophy of psychology retains points of contact with logical behaviourism. It rejects the dualist account of the mental as inalienable and epistemically private. It accepts, albeit as an empirical fact, that language-learning (and thereby the possession of a complex mental life) is founded on brute 'training' (Abrichtung), rather than genuine EXPLANATION, and presupposes natural patterns of behaviour and reaction, to be activated by certain stimuli. And it claims that the ascription of psychological predicates to other people is logically connected with behaviour ${ }^{19}$. However, Wittgenstein's connection in his later philosophy to logical behaviourism is not sufficient to assert that he was a behaviourist - indeed methodological behaviourism and logical behaviourism are sufficiently distinct, and similarly even though he systematically rejects cognitive analysis he does not deny the existence of a complex mental life, particularly when he refers to mentalistic concepts:

'We are tempted to think that the action of language consists of two parts: an inorganic part, the handling of signs, and an organic part, which we may call understanding these signs, meaning them, interpreting them, thinking. These latter activities seem to take place in a queer kind of medium, the mind; and the mechanism of the mind, the nature of which, it seems, we don't quite understand, can bring about effects which no material mechanism could ${ }^{20}$.

One of the best ways to understand language-games is to see them as a network of connections, or at least producing an understanding that allows one to see connections. Furthermore, while language-games are primitive forms of language they are supposed to be 'complete'. Teaching practices, by contrast, are fragments of language:

'They are more or less akin to what in ordinary language we call games.....W We are not, however, regarding the language-games which we describe as incomplete parts of a language, but as languages complete in themselves, as complete systems of human communication...2 ${ }^{21}$.

Wittgenstein tried to show that not all meaningful uses of language are meaningful in the same way; for example, names derive their meaning from a definite association or correlation with a specific object or person; however, not all words are names - the thing or person that is the bearer of the name is not itself or herself the meaning of the name $e^{22}$.

\footnotetext{
${ }^{19}$ Glock, H. A Wittgenstein Dictionary, Oxford: Blackwell Publishing, 1996: 57.

${ }^{20}$ Wittgenstein, L. cited in: Monk, R., How to Read Wittgenstein, London: Granta Books, 2005: 74

21 Wittgenstein, L. The Blue Book, London: Blackwell Publishing, 1958: 81.

${ }^{22}$ Monk, R. How to Read Wittgenstein, London: Granta Books, 2005: 73.
} 
Was Wittgenstein a behaviourist? is undoubtedly a contentious question and one that has been asked by not only many eminent psychologists but also by philosophers, scholars and critics. It is a factious area of enquiry with many complex matters to consider before any judgement can be made. In psychology, behaviourism is the view that human activity is accounted for by descriptions of one's behaviour. For example, Mary Jo is visibly upset. The description of her behaviour includes using the terms crying, anxious and sobbing; it is from observing Mary Jo's behaviour - crying, anxious and sobbing - that one can give an account or description of her behaviour. However, in philosophy, and in particular with reference to the philosophy of mind, logical behaviourism argues that one's mental concepts can be defined in terms of one's behaviour, in the sense that statements about one's mind can be translated into statements about one's behaviour, thus there is an interconnection between concepts and behaviour, and mind and behaviour. The general term 'behaviourist' has been applied to Wittgenstein, perhaps only because he places an emphasis on meaning and 'meaning as use' within a social context (how one is using language), and yet no detailed examination and specific definition of the type of behaviourism he is supposed to have held is available. Thornton argues that there are close ties between mental states and behaviour. Because mental states content depends on linguistic content, being able to form mental states requires underlying practical abilities to use and explain signs. These practical abilities pay a constitutive role in the formation of mental states. Thus, there is an apriori and analytic connection between mental states and behaviour. However, one has to ask whether that connection is sufficient to warrant the generality of Wittgenstein being labelled a behaviourist? ${ }^{23}$

Behaviourism, as a prominent paradigm in the 1940s and 50s, placed an emphasis on the study of learning rather than focusing on psychological functioning; behaviourists were interested in seeing and understanding the effects of stimulus-response reactions that which is considered to be 'observable' and 'objective' as opposed to that which is 'inward' or a form of introspection both of which are neither observable or objective. When Wittgenstein was working on the Investigations, behaviourism was at the same time concerned with attempting to put forward a 'theory of behaviour'. (One could arguably align this with the assertion that Wittgenstein's language-game, as explicated in the Investigations, similarly constitutes a 'theory of language'.) The proposed theory of behaviour was based on the principles of conditioning, S-R reactions, and on environmental determinants of behaviour. (However, some problems that have been associated with behaviourism include the issue that environmental stimuli are accounted for while internal factors such as past knowledge and experience are ignored. It is because of dissatisfaction with behaviourism that the development of the cognitive approach was born.)

Without exception, logic would have played an important role without Wittgenstein, due mainly to Frege, Russell and Carnap but it was Wittgenstein who provided a powerful methodological rationale for its role, and who brought language into the equation ${ }^{24}$. He characterises logical truths not in terms of form or structure, but by reference to linguistic behaviour. He views language as essentially guided by norms. It is this normativist conception of language which allows him to make sense of, rather than to reject, the notion of logical necessity ${ }^{25}$. The Investigations shows clearly how Wittgenstein abandoned logical atomism but retained the idea of a 'phenomenological'

\footnotetext{
23 Thornton, T. Wittgenstein on Language and Thought: The Philosophy of Content, ,Edinburgh: Edinburgh University Press: 1988: 120.

${ }^{24}$ Glock, H. A Wittgenstein Dictionary, Oxford: Blackwell Publishing, 1996: 28

25 Ibid.: 135
} 
primary language hidden beneath the surface of ordinary language ${ }^{26}$. Wittgenstein wanted to write a book to continue, and later to correct, his earlier work (The Tractatus). For many, as Bryan Magee states, to understand Wittgenstein is to understand his 'matter' and thus it is no surprise to observe how often he has been misunderstood and misinterpreted, by both scholars and critics. The Investigations is exemplary of this: Wittgenstein never suggests that language is a 'game' but that language is similar to games in terms of its network of connections and family resemblances. Furthermore, because of the structure and terseness of the Investigations, the complex nature of the languagegame can be difficult to access and understand; nonetheless the Investigations is a continuation of his ideas about language and its constituent parts: ontology, semantics and syntax. It is questionable whether Wittgenstein ever abandoned the calculus view of language. However, by the time the Blue and Brown Books were circulating he had replaced the term 'calculus' with 'language-game' and thus this would indicate a definite shift in his conception of language. However, both the calculus and language-game are rule-governed but it is Wittgenstein's conception of these rules, and their application, that has altered: if anyone utters a sentence and means or understands it he is operating a calculus according to definite rules ${ }^{27}$. Wittgenstein claims that the calculus view of language does not reflect the essential nature of reality but is autonomous. For him, the 'meaning' of a mathematical sign, like that of a chess piece, is the sum of the rules that determine its possible moves ${ }^{28}$. What differentiates applied mathematics and language from chess and pure mathematics is merely their 'application', the way in which they engage with other (linguistics and non linguistic) activities ${ }^{29}$. Just as the calculus view of language highlights similarities between language and formal systems, the term languagegame highlights the similarities between language and games, and thus the link to behaviour can be seen yet again.

A further anomaly in Wittgenstein's alleged allegiance to behaviourism can be identified when he suggests that language is impossible to transcend and that it can never be explained from an 'outside' perspective but is only explicable from within the workings of language itself: language is obscured when 'instead of looking at the whole language-game, we only look at the contexts, the phrases of language in which the word is used $^{30}$. (One could argue here that when he denies the explanation of language from an outside perspective he is in fact disclaiming a form of behaviourism.) The language-game is language in action, and for Wittgenstein as a logical behaviourist it is also language as behaviour. Speaking a language and using words is an analogy to playing games, also behavioural: both (using words and playing games) are human activities, social and shared communal processes that are systematic and are rule-governed. However, although he did not abandon the idea that language is rule-governed, he clarified it, comparing language no longer to a calculus but to a game. Unlike these analogies, the idea that language is rule-governed is not just a heuristic device; understanding a language involves mastery of techniques concerning the application of rules. Wittgenstein continues to stress the link between language, meaning and rules (ontology, semantics and syntax) $)^{31}$ : 'following according to rule is FUNDAMENTAL to our language-game ${ }^{, 32}$.

\footnotetext{
${ }^{26}$ Ibid.: 23.

27 Wittgenstein, Ludwig Philosophical Investigations, Oxford: Blackwell, 1953: \#81.

${ }_{28}^{8}$ Glock, H. A Wittgenstein Dictionary, Oxford: Blackwell Publishing, 1996: 23.

${ }^{29}$ Wittgenstein, Ludwig in Ludwig Wittgenstein and the Vienna Circle (1929-1932) 103-5, 124, 150-1, 163, 170; MS 166 28-9; Laws II \#88; cited in Glock, H. A Wittgenstein Dictionary, Oxford: Blackwell Publishing, 1996: 193.

${ }^{30}$ Wittgenstein, L. The Brown Book, London: Blackwell Publishing, 1958: 108.

${ }^{31}$ Glock, H. A Wittgenstein Dictionary, Oxford: Blackwell Publishing, 1996: 151

${ }^{32}$ Wittgenstein, L. Remarks on the Foundations of Mathematics [1937-44], ed. G.H. von Wright, R. Rhees \& G. E. M. Anscombe, tr. G.E.M. Anscombe, re. edn, Oxford: Blackwell, 1978:330.
} 
Both language and games are contextual and share several features rather than one defining characteristic that suggest how they should be categorised. However, although the language-game is rule-driven, the rules are applied loosely as opposed to strict and rigorous rules that one might apply to science. A language-game does not always follow strict rules:

'It is not everywhere circumscribed by rules; but no more are there any rules for how high one throws the ball in tennis, or how hard; yet tennis is a game for all that and has rules too. ${ }^{33}$

A language-game refers to a social based context where human beings relate to, engage with and understand one another. As in games, a language-game will have (or develop) its own rules for understanding and interpreting the many and varied aspects of its use of language. However, this does not prevent contradictions or some confusion arising when aspects of one language-game may be set aside with similar aspects to another language-game.

Wittgenstein's philosophy of mind has often been interpreted - or arguably misinterpreted - as a form of behaviourism. However, as a behaviourist, or perhaps a philosopher with behaviourist viewpoints, he introduced language in a broader context and with no specific link to cognitive processing. Wittgenstein asks how does language function in life and what roles does language play in human thinking and in human behaviour, and it is these fundamental questions that separate him from a behaviourist stance and anchor him firmly in logic and language. Similarly, his interest in establishing broader descriptions as opposed to concrete definitions distinguishes his language-game as innovative and impossible to describe. Furthermore describing or labelling Wittgenstein as a behaviourist is arguably a profound misconception of his work and distorts any potential appreciation and understanding of his philosophy. Perhaps all one can conclude is that while he was open to some vague behaviourist assumptions within the paradigm of psychology at the time of the Investigations, he was without doubt and exception, a logical behaviourist in the fullest sense, and remained so even as he undermined positivism in his later works.

Perhaps, at best, we are left asking the more relevant and integral question: would Wittgenstein have clarified his position in his psychological writings in philosophy if he knew how much he was going to be misinterpreted and misunderstood, particularly in relation to behaviourism?

\footnotetext{
33 Wittgenstein, L. Philosophical Investigations, Oxford: Blackwell, 1953: \#68.
} 
